\title{
Towards a "Negative Aesthetic": Bombay Talkies and the Queer Futures of Popular Hindi Cinema
}

\author{
Sameer Chopra \\ Gargi College, University of Delhi, India.Email:sam1565@gmail.com. \\ Received February 25, 2017; Revised April 9, 2017; Accepted April 10, 2017; Published May 7, 2017.
}

\begin{abstract}
This paper examines emerging trends in contemporary representations of queerness in popular Hindi cinema in an attempt to argue against the bourgeoning popularity of "positive images," i.e. sanitized, tractable portrayals of queer lives on screen that find recognition among sections of mainstream audiences so long as these depictions resonate with one's desire to see characters who are reassuringly "like us." This sets forth a normalizing agenda that deems queerness intelligible only when it is shorn of its subversive, destabilizing potential. As a counter-narrative to this trend, I study two shorts compiled in the 2013 anthology film, Bombay Talkies- essentially, my contention is that both these texts feature protagonists (Avinash and Vicky) who are not "positive" or likeable in any reductive sense. Nonetheless, they embody, in their own peculiar ways, the revolutionary potentialities of queerness. It is precisely for this reason that Bombay Talkies can be considered representative of a negative aesthetic, a term that consciously draws from John Keats' notion of "negative capability" and its emphasis on embracing "uncertainties, mysteries, [and] doubts, without any irritable reaching after fact and reason" (1818, p. 498). The textual and ideological open-endedness and variability intrinsic to Keats' concept may help us evolve an interpretive framework that interrogates the prevalence of narrow, "either/or," "good/bad" representational paradigms specifically geared towards rendering queerness "normal" and "acceptable" in the popular consciousness.
\end{abstract}

Keywords: LGBT, queerness, representation, popular Hindi cinema, negative aesthetic

\section{1) Introduction}

... there is no single correct way to queer popular culture ... the queering of popular culture has taken multifarious forms, has focused on different issues, and has drawn on a range of theoretical

positions. (Sullivan, 2003, p. 189)

In an article titled "Dear Karan Johar, do you really think gay men are like this?," published in First Post, columnist Sandip Roy (2013) criticized Ajeeb Dastaan Hai Yeh -Karan Johar's short in the 2013 anthology film, Bombay Talkies ${ }^{1}$ - for its supposedly biased and offensive portrayal of gay characters and their lives. Berating the director for the lack of social responsibility, Roy stressed how Avinash (Saqib Saleem), the edgy, provocative protagonist of the film, comes across as "emotionally unstable, unable to have any conversation without gratuitous sexual double entendres, self-destructive, masochistic, and prone to kiss-and-tell" (para. 5), thus buttressing the enduring stereotype of the homosexual as a predator. It is in questioning the moralizing force of Roy's arguments that my paper attempts to frame Bombay Talkies as a paradigm-shifting text, in that it gestures towards heterodox, non-linear futures of queer representation in popular Hindi cinema. Contemporary media discourse on queerness and visual representations has largely underscored the need to question the power of "negative" portrayals and evolve more "balanced,"

(c) AesthetixMS 2016. This Open Access article is published under a Creative Commons Attribution Non-Commercial 4.0 International License (http://creativecommons.org/licenses/by-nc/4.o/), which permits non-commercial re-use, distribution, and reproduction in any medium, provided the original work is properly cited. For citation use the DOI. For commercial re-use, please contact editor@rupkatha.com. 
"rounded" ones, thereby assessing queer characters narrowly in terms of their credentials as role models (Sharma and Sundar, 2016). Films and characters are either condemned for adhering to representational clichés or celebrated for challenging them, this reductive approach frequently justified by apprehensions about the impact of these images on viewers' attitudes. What constitutes a positive queer character, however, remains highly contentious: a simplistic categorization of images as positive or negative fails to take into account the complex ways in which viewers interpret texts and, further, issues of cross-gender identification. With a new emphasis on complexity, diversity and fluidity, filmmakers are now beginning to see an undue reliance on positive images as an attempt to domesticate the subversive potential of queer identity and normalize it in the popular imaginary.

The critical importance of Bombay Talkies can be located in its relevance to ongoing debates about the inherent desirability of "positive" portrayals of queer individuals on screen. Do positive representations and the rhetoric of inclusion spell the end of queer culture? Is the "acceptance" of queers predicated on homogeneity rather than difference? In the Western academia, a more confrontational, anti-integrationist strand of queer politics has begun contesting the need for politically-correct images in favour of open, unfettered, multilayered portrayals that offer, in Michael Warner's (1993) terms, a "thoroughgoing resistance to the regimes of the normal" (p. xxvi). From this perspective, Bombay Talkies can be seen to register a marked departure from politically amiable, yet ultimately limiting films such as the criticallyacclaimed My Brother . . . Nikhil (2005, dir. Onir), insofar as it refuses to feature idealized, desexualized and monochromatic characters and plotlines that pander to heteronormative expectations. Resisting the righteous imperatives of assimilation, acceptance and "balanced" sociability, queer subjectivity in Bombay Talkies appears to be constructed through a far more oppositional matrix. In other words, the film takes the "abnormality" of its queer characters so fully for granted that it does not for once seek to portray them in unrealistically sympathetic or flattering terms. It also broadens the discourse of queer representation by exploring hitherto unchartered themes of "transgender" identity, cross-dressing and the unfixed, perennially shifting relationship between sexuality and biology. This is especially significant in the context of massmedia representations in India, where the cross-dresser is invariably a figure of mirth and derision. In effecting these thoroughgoing departures, Bombay Talkies foregrounds what I provisionally term a negative aesthetic, one that conceptualizes queerness as a locus of radical, deterritorializing difference rather than rehabilitative sameness.

\section{2) Queerness as “Negative” Excess: The Case of Avinash}

Why is Saqib a home breaker at the end of it? . . . He actually goes and breaks a marriage . . . As a filmmaker, I loved the film, but as an activist, as a person, I just feel it sets back things for us [the LGBT community]. ("In Conversation with Karan Johar . . . and Sridhar Rangayan"- The Front Row with Anupama Chopra)

Gay documentary-maker Sridhar Rangayan's comments on Ajeeb Dastaan Hai Yeh, cited above, are emblematic of the dualistic frameworks that are often invoked to engage with queer characters and stories in mainstream media and certain activist circles. It must be emphasized here that artistic representations of queerness need not be programmatically accountable to a social movement; nonetheless, why Rangayan thinks Bombay Talkies does not adequately serve the "gay cause" is an important line of enquiry for our purposes. As he spells out, it relates to his apprehensions about the portrayal of Avinash (the protagonist of the short-film), with regard to precisely whom I venture to principally disagree with Rangayan's contention, and indeed, with 
the entire project of constructing a "normal" queer character who would apparently set things forward for the community. Avinash may not be the prototype of "goodness" or likeability, but considered from another, markedly queer perspective, he opens up, for himself and those around him, radical possibilities of re-negotiating subjectivity, identity and space. Ajeeb Dastaan begins on a thoroughly disconcerting note: a bewildered Avinash hauls his sleeping father out of the bed, screaming, "Chakka nahin hu main, homosexual hu ... na chakka hona galat hai, na homosexual hona" (I am not a eunuch, I am a homosexual . . and being neither is wrong [my trans.]). While his parents are still struggling to come to terms with this sudden burst of explosive anger, Avinash leaves the house never to return. Even at this early juncture in the narrative, the plot establishes him as a confrontational, aggressive character who does not seek assimilation into his dysfunctional family. In fact, his assault is directed as much at his father as the discourse of family itself, recognized here as the institution "that . . . naturalizes compulsory heterosexuality, delegitimizing potential flows of desire along innumerable and unpredictable dimensions" (Menon, 2007, p. 36). Over the course of the next few sequences, Avinash appears as an intern in a newspaper office bonding with Gayatri (Rani Mukherjee), an Associate Editor in the same organization. They grow close and Gayatri invites Avinash home for a dinner-treat on his own birthday. On a mere instinct, he conjectures that Dev (Randeep Hooda), Gayatri's husband, is a closeted homosexual, and begins secretly courting him. This precipitates a whirlwind crisis, leaving Dev a broken man, publicly exposed for his inability to come to terms with his sexuality, while Avinash faces no final judgment. Only Gayatri attains liberation at the end: she walks out of a loveless marriage to embrace an affirmative future for herself.

Portrayed as obsessive and convoluted, - and therefore not "positive" in any narrow sense of the term - the protagonist of Ajeeb Dastaan is a hyper-sexualized character who pursues his object of desire with a relentless, almost predatory energy. This, however, is also the source of his subversive and de-traditionalizing potential; his speech is laced with sexual innuendo, and he does not respect niceties of "decent," "public" conduct, quipping at Gayatri's dinner table, "I am gay but I don't bite, unless somebody wants." Again, he flirts with Dev unabashedly, much to the latter's displeasure: when Gayatri proposes that the two men go together to Dev's "special room" where his coveted music collection of old Hindi classics is stacked - Avinash replies he is willing to go with Dev to "any room," making his sexual interest in his best friend's husband blatant. Eventually, Avinash reaches Dev's workplace, and in an unprecedented move, nuzzles Dev's neck sensually in front of all his colleagues, inviting a vicious assault upon himself. Dev's visceral outrage can be considered a reaction to being stalked by another man in a decidedly nonprivatized, "official" setting, the substratum of his patriarchal prestige, social standing and "manliness." In an attempt to establish physical intimacy with the same gender openly, Avinash has in effect fractured the social contract that zealously categorizes space into "private" and "public" domains in order to protect the unseen, unmarked privileges of a heteronormative culture. Queer theorists have pointed out how non-normative sexualities can potentially occupy social spaces in ways that impede the unhindered circulation of "straightness." Berlant and Warner (1998) discuss ways in which contemporary heterosexism "naturalizes" itself "through the ideologies and institutions of intimacy" (p. 553) that permanently consign sex and sexuality to the private sphere, thus regulating how and where queer intimacies may (and may not) be legitimately experienced and expressed. In view of such an understanding, Avinash's impetuous expression of desire for Dev in public is a defiant, politically charged act that configures queerness as a disruptive force impervious to the hollow sanctities of a sexually duplicitous culture.

The other instance that crystallizes the revolutionary character of queerness is, of course, the kiss between Avinash and Dev. In personally experiencing it unfold in the dark of the cinema 
hall, I sensed it repulsed many viewers, especially men, some of whom could be heard sniggering, letting out a collective gasp of laughter to absorb the disorienting effects of what they had just witnessed on screen. Two remarks that I happened to overhear are reproduced here from memory: a) "Yeh Karan Johar hai na homo, sab ko homo banake chodega" (Karan Johar is a homo himself, he will turn everybody else a homo [my trans.]) b) a gym-built man, possibly claiming a vague sense of regional affinity with Randeep Hooda's Haryanvi roots, muttered to his friend: "Arre bhai yeh Randeep Hooda ne toh naam kharaab kar diya" (Oh brother, this guy Randeep Hooda completely let us down [my trans.]). These derogatory assertions evidence not only the obvious homophobia the dissident moment of the kiss generates but also how it threatens to undermine the Hindi cinemagoer's preconceived relationship with the screen. Madhava Prasad (1998) examines culturally specific responses to the on-screen spectacle of the kiss through the religious theory of darsana, "a relation of perception within the public traditions of Hindu worship . . . constituted by the combination of three elements: the divine image, the worshipper and the meditating priest" (p. 75). Though acknowledging that the ban on the kiss in popular Hindi films is of an informal nature, not enshrined in any post-independence censorship laws, he attributes its relative absence on screen to the other, more potent law of the samaj- the underlying socio-religious convictions of the majority that views such an act as a transgression of morality. The kiss may be "private" in the context of the particular narrative situation, but it is still "public" insofar as it is displayed in the cinema, hence validating the need to censor it. This thesis correctly approximates the overbearingly reactionary perspectives that an average Indian spectator brings to bear upon their viewing practices. Even as the impact of liberalization and globalization has somewhat lessened the shock of viewing the (heterosexual) kiss on screen, the homosexual kiss is a sight that still agitates the spectator, forcing them to admit altered and alternative frames of reference within their line of vision.

As a narrative moment of significant disruptive potential, the kiss between Avinash and Dev also leads to the unraveling of heterosexual marriage, another institution, like cinema, mired in the conventions of the samaj. Once again, without any regard for public "decency," Avinash interrupts Gayatri in the middle of a meeting to tell her that Dev kissed him. Infuriated and visibly at a loss for words, she comes home and finally puts an end to her barren marriage. "All these years," she tells her crestfallen husband, "all I did was to live a lie ... I feel happy now, I feel free." The parting shots of the film enact her metamorphosis into an assertive, self-assured and, above all, sensual individual. Provocatively dressed, pleasuring herself longingly, even narcissistically, Gayatri reconnects with her erotic self hitherto annulled by Dev's cleverly orchestrated charade of heterosexuality and cis-masculinity. Similarly, when Dev finally confronts himself for who he is, he seems shattered, but also paradoxically on the verge of a new beginning. Sitting aloof on a railway platform, he finds a strange sense of solace in the way an urchin's song resonates with his own life. To my mind, it is not incidental that Johar sets up Avinash as a catalyst for these profound transformations, precarious and tentative as they are. Through his brashness, lack of decorum and impatience with the proprieties of heteronormativity, he helps both Gayatri and Dev come face to face with the unpleasant yet ultimately fundamental truths about their existence that they had buried under layers of social posturing. Queerness, then, is indeed a "negative" energy, insofar as it ruptures the constrictive, dehumanizing scripts of social viability and acceptability. In his willingness to embrace conflict, turmoil and alienation as the organizing principles of his socially-maladjusted self, Avinash facilitates the unmaking and remaking of identities, the awakening of sexualities and the unmooring of subjectivities from the pressures of finding legitimization in a culture that thrives on the submergence of the affective and the individual in favour of the collective and the social. 
The belief that such a character upsets the clamour for "positive" images masks, in my opinion, the fear of queerness as an itinerant excess that resists being corralled into dominant, culturally-sanctioned ways of seeing and being. Indeed, queer characters who are depicted in an unfailingly "positive" light in our cinemas are sometimes also idealized to the extent of being divested of all their sexuality, thus rendered palatable for mass-consumption. Nikhil Kapoor (Sanjay Suri), the eponymous protagonist of My Brother . . Nikhil, is a particular case in point. A poignant story of the marginalization and death of a swimming champion who is both gay and HIV positive, the film quite laudably highlights mutual respect and care giving in Nikhil's relationship with Nigel (Purab Kohli), his long-time boyfriend, but in so doing, simultaneously desexualizes it, never even identifying the two protagonists as "gay" in the first place. Unsurprisingly, media responses to the film either chose to ignore that Nikhil and Nigel were romantic partners, or, at best, acknowledged how their relationship appeared completely "normal" in the film. Writing in the Outlook, Namrata Joshi (2005) opined:

The gay relationship here is not designed to shock the audience or make them feel queasy but is so "normal" that the two lovers seem just like any other couple ... It is the love and faith that matters, whether it is man-woman, man-man or woman-woman. (para. 1)

Joshi's views on the film seem oblivious to the fact that the "normality" the gay relationship in $M y$ Brother . . . Nikhil somehow so effortlessly exudes is a discursive effect, achieved through a deliberate excising of the explicitly corporeal aspect of the bond between the two men. The primary affect through which the relationship is structured is "love:" while ostensibly a progressive manoeuvre in its ability to imagine non-platonic same-sex associations as comprising more than just sexual greed, it is also a curiously defensive one, anxious to ensure that audiences never feel discomfited about the couple. The "normal" gay relationship, in this case, is also the normative one, chaste, privatized and monogamous. Correspondingly, Nikhil himself is a strangely reassuring character, emphatic about his decisions and to that extent rebellious, yet eager to be absorbed back into the family as a good son and brother. Unlike Avinash, Nikhil endears himself to the spectators, never impelling them to reflect on their deeply engrained assumptions and biases about identity and selfhood. He is always "one of us," and his relationship with Nigel, to quote Joshi once again, "just like any other couple." The gaze that My Brother ... Nikhil constantly, even obsessively, mobilizes towards Nikhil is one of sympathy and compassion; consequently, and this is one of the most troubling paradoxes of the film, he emerges as the "good," idealized homosexual despite dying of AIDS. By the end of the narrative, his moral rehabilitation is fully achieved; his parents, and by extension the audiences, are made to feel tremendously guilty of being dismissive of his life-choices. The societal "other" is, hence, cathartically transformed, made to emotionally belong to the very heteronormative structures that alienated him in the first place. Avinash, on the other hand, remains perennially unhappy and nomadic, without a stable "home" to return to; ironically, he seems all the more liberated for it. His risqué, even problematic disposition destabilizes our most cherished configurations of the "normal," including conventional gender roles, the hegemonic regimentation of space, the sacrosanct status of marriage and reproduction and notions of (homo-) erotic and romantic coupledom that merely replicate heterosexist frameworks. He does not so much strive for "inclusion" within the dominant order, instead becoming - to borrow Bose and Bhattacharyya's (2007) theorization of the "queer" as an "alternatively sexualized citizen," - "instrumental . . . in rendering unstable all universalized notions of citizenship (modelled on the male heterosexual)" and "threaten[ing] the social ... boundaries of the national imagination ..." (p. xvii). 


\section{3) “I Don't Want to Learn Football”: Sheila Ki Jawani and the Crisis of Gender}

There is zero tolerance for those who breach the carefully produced 'natural' order of society by refusing to conform to norms of looks and behaviour. (Menon, 2012, p. 3)

Popular Hindi cinema routinely features men adopting "feminine" dress and mannerisms, but rarely is this considered a genuine expression of gender liminality. Thus, cross-dressing gets customarily reduced to a comic interlude- a temporary aberration that the male hero participates in, either to entrap the villain or gain proximity to the heroine and her friends. In Baazi (1995, dir. Ashutosh Gowariker), for instance, Aamir Khan transforms himself into a seductress, successfully luring the villain who harbours an impression that he might happen to have sex with "her." Instead, Khan dramatically takes his drag off and bashes the villain up, hence reinstating the power of his hypermasculinity and negating possibilities of queer affirmation latent in crossdressing (Gopinath, 2000, p. 292). In other examples, such as the popular eighties' song "Mere Angne Mein Tumhara Kya Kaam hai," the political edge of the act is blunted by being rendered comic. The cross-dressing actor is typically a source of self-congratulatory humour; the "masculine" body of the tall, broad-shouldered superstar, Amitabh Bachchan, "seeps through" as the audience is made doubly aware of his essential "maleness" that remains unsullied by the potentially unsettling effects of cross-dressing. In such a scenario, the cross-dresser is invariably presented as one sex masquerading as the other, and seldom as an autonomous (non-) category, a thirdness beyond the male-female binary.

It is in this context that we can situate the critical significance of Sheila Ki Jawani, Zoya Akhtar's short in Bombay Talkies. The plot of the film centres on a twelve-year-old boy named Vicky (Naman Jain) who has no interest in sports and other "boyish" pursuits. Rather, he aspires to be a dancer; not unexpectedly, this becomes an abiding source of unease for his father, Ashok Sharma (Ranveer Shorey).Vicky is an ardent admirer of Katrina Kaif, a well-known Bollywood actor, and is greatly inspired when he witnesses her harping on the importance of breaking societal taboos and following one's dreams in a television interview. In a particularly poignant sequence that follows, he is "caught" cross-dressed and dancing and is harshly rebuked for it. Meanwhile, Vicky's sister, Kavya (Khushi Dubey), wants to go on a historical excursion organized by her school, but her father is reluctant to sponsor it, having already spent enough on Vicky's football training. This disappoints Kavya: why should her father force Vicky to do something the latter is utterly disinclined, even indifferent, towards? Eventually, the brother manages to save the day for her by dancing to "Sheila ki Jawani" (Kaif's chartbuster that is repeatedly invoked in the film, including its title) before a local audience. It is evident throughout the film that for Vicky, cross-dressing is not an "act" or a comic pastime, but an identity-concern. Clearly a misfit on the football field, he identifies more with the Bharatanatyam sessions in his school, his mother's dressing table and Kaif's seductive dance moves. In the highly symbolic beginning of the narrative, several children, unmistakably coded as cisgender, spell out what they want to grow up to be: a girl professes her desire to be "Miss India" while the boys variously proclaim their aspirations to be a jockey, superman, astronaut, police officer and businessperson. It becomes evident here how heteronormative expectations of desirable gendered behaviour are concentrated in, and reproduced through, the figure of the child. Vicky throws gender into a flux because he "lacks" the sportiness and athleticism supposedly "natural" to males and refuses to discipline his body and subjectivity to conform to the stultifying demands of a binaristic gender code that neatly defines individuals as "male" or "female" only. In the very embodiment of his ambivalent and gender-fluid identity, then, Vicky reveals gender norms to be cultural artefacts mobilized to keep a particular social-order intact. 
Returning from one of his many forced-visits to the football field, - unable to comprehend the specious logic behind so many boys ceaselessly chasing a ball -Vicky unequivocally tells his father, "I don't want to learn football." The father's response is deeply instructive: "Kya accha nahin lagta, that's not important. Kya accha hai, woh important hai. Football kheloge toh tough banoge" (What you like or do not like is not as important as what is good for you. If you play football, you will become tough [my trans.]). Seemingly, Vicky's father is more considerate than Avinash's; nevertheless, through his matter-of-fact, "fatherly" admonitions, he still attempts to coerce Vicky to comply with the discursive scripts of masculinity. The violence that these efforts perpetuate becomes far more explicit when Vicky chooses to positively assert his identity as a gender-transgressive person. On one occasion, he decks himself up in his sister's clothes, and his mother's lipstick, sandals, necklace and earrings, gyrating uninhibitedly to a Bollywood number, completely unselfconscious of doing something "wrong." As a result, his father thrashes and warns him of adverse consequences, should such a "mistake" be repeated:

Yeh joke hai? Yeh kaisa mazaak hai? . . . Ye kya bana rahe ho tum log isko . . . [to Kavya] Yeh tumhara bhai hai ... . [to Vicky] Aur tum . . . kya bann rahe ho tum . . . kya banoge bade hokar?" (Is this a joke? What is all this? What are you all trying to turn him into? [to Kavya] He is your brother! [to Vicky] What are you trying to become? What will you grow up to be? [my trans.])

In his utter inability to articulate a viable future for his son, Vicky's father expresses barelyconcealed apprehensions that his son's pleasurable sojourns into the realm of cross-dressing and gender dissidence may eventually turn into permanent fixtures of his identity, thus undermining heteronormative patterns that constitute proper "growth" and "maturation" only in terms of (heterosexual) marriage and reproduction. In an influential study, Edelman (2004) critiques the repressive ways in which heterosexist ideologies seek to impose a "compulsory narrative of reproductive futurism" (p. 21) on the socially-fraught figure of the child. The "queer," on the other hand, metaphorically embodies the Freudian notion of thanatos (or the death instinct), a force of "negativity opposed to every form of social viability" that "dismantles the subject from within" (p. 9). Such a formulation helps us better analyze the father's objections to his son's non-normative behaviour: Vicky may have indeed embraced his queerness so fully that any attempts to plot him back into socially acceptable trajectories of self-construction would likely prove futile.

In stark contrast, Kavya does not seem particularly mortified by her brother's gender non-conformism. In fact, she cheerfully embraces Vicky's "femininity" as an extension of her own, nurturing a new, queered relationship with her brother, one that is a deliberate counterpoint to the nationalist construct of the "family," a formation critical to the dissemination of "institutionalised gender inequality . . . patriarchal authority, . . . [and regressive] ideas about masculinity and femininity" in Hindi cinema (Virdi, 2003, p. 12). The sibling bond subverts from within the hegemonic schema wherein the brother acts as a "manly" guardian policing the physical and moral limits of female autonomy and sexuality. If anyone is the protector in this case, it is the sister- silently, but assuredly, Kavya continually keeps Vicky from harm, most notably when, sensing another round of psycho-physical violence becoming imminent for her brother, she lies to her father about a new Katrina Kaif poster plastered on the room's wall being hers. This mutually-supportive, egalitarian ethos that Kavya and Vicky foster transforms the "home" from a space constituted through a differential access to power and reified notions of male potency and female passivity to one that enables the proliferation of gender malleability and inversion of codes that govern man-woman relationality. For Vicky, 
this process of reimagining the home is especially liberating because it is precisely the site where the opprobrium for his queerness is most obviously manifest. Worried about her father's severe censuring of Vicky's cross-dressing ways, Kavya instructs him it is possibly due to his desire to be like girls. Vicky's response is profoundly radical for the completely nonchalant manner of its articulation: "Toh? . . Ladkiyon mein kya burai hotti hai? (So? What is wrong in being like a girl? [my trans.]) In a moment of spontaneous self-correction, Kavya relinquishes whatever little "concerns" she had previously harboured about her brother's conduct, and extends her hand towards his, signalling her empathetic appreciation of Vicky's unwillingness to plot himself on a masculine-feminine binary. Indeed, there is a distinct sense throughout the narrative that Kavya finds Vicky's dissident identity personally enabling too; understandably, then, Vicky soon acquires the courage to emphatically declare to her: "Main jaanta hu main bade hoke kya banunga . . . dancer, Sheila ki tarah!" (I know what I will grow up to be ... . a dancer, like Sheila! [my trans.]).

The concluding sequence of the narrative, its most uplifting and remarkable, is in many ways enabled through this progressively reconstituted bond between Vicky and Kavya. As Vicky offers to dance at an informal, ticketed event to raise funds for his sister's school-trip, the initial nervousness and embarrassment he experiences about being introduced as "Sheila Sharma" on stage is masterfully captured by Akhtar in close, low-angle shots. Encouraged by Kavya, however, the awkwardness soon gives way to gaiety and exultation at finally being able to celebrate one's gender-transgressive identity. The camera zooms on Vicky to give the viewer a conspicuous sense of his reserve fading into an uninhibited and liberating dance performance. Dance, traditionally considered a "feminine" pursuit, becomes for Vicky a source of emancipation from the debilitating tyranny of traditional gender mores, as the audiences (both in the film and in the cinema) witness the transformation of a shy, alienated and introverted boy into a consummate diva. The psychoanalytically defined category of the "sexual invert," a negative signifier of libidinal arrest, here emerges as an exceptionally powerful figure, one who quite literally embodies multifarious challenges to the inequities of heteronormative social arrangements. In his ability to re-conceptualize not simply the oppressive power of normative gender roles, but also his relationship with his body, his sister, and the phallocentric world around him, Vicky personifies, like Avinash, the politically subversive potentialities of queerness. Contrary to formulaic expressions of cross-dressing that paradoxically over-determine one's "real" sex, Vicky's participation in the act leads to a comprehensive refashioning of his selfhood, highlighting "the epistemological rift between gender signifiers and their signifieds ... [and] the fiction of a unitary psychosocial gender that is rooted biologically in corporeal substance" (Stryker, 1998, p. 147).

\section{4) Conclusion: Whither Normal?}

Ellis Hansen (1999) observes that every film with queerness as its thematic preoccupation is inevitably embroiled in the moralistic debate about its didactic significance, "as though art were to be valued only as sexual propaganda" (p. 11). This paper has sought to argue that "goodness" or "badness" need not ultimately be the most significant interpretive optics for analyzing queer representation; the discourse itself has to shift from an over-insistence on reductively "positive" gay characters to more open-ended, diverse "queer" ones, thus enabling the circulation of unconventional, subaltern perspectives on sexuality and identity in popular culture. We may do well to nuance our critical positions to recognize the need for multiple interpretations and responses on this issue rather than imposing a readymade template of sanitized representations. A complex, thoughtful delineation of queerness on screen cannot simply be a matter of coming 
across as socially well-adjusted or likeable; it should ideally challenge cultural norms that produce the queer individual as an eternal other in the first place. If Avinash achieves this through his disquieting irreverence towards the rules and codes that govern unquestioningly acceptable patterns of sociability, Vicky does so in ways far more fundamental to his very self-concept as a gender-transgressing person. It is in this sense that they can be considered harbingers of a new negative aesthetic of queer representation in popular Hindi cinema, one that is not overtly preoccupied with the construction of queerness as "normal" or non-threatening for the mainstream viewer. Seen in conjunction, both the characters offer counter-positions to the evolving cinematic orthodoxy around the figure of the "good" homosexual who seeks assimilation into the family, and larger society, by repressing any traces of defiant excess that might mar his utility as a prototype. Hostile representations of homosexuals as effeminate, predatory and selfloathing have recently been questioned for being offensive, and with that has come an assumption that homophobic portrayals can simply be replaced by "positive images." Queer reflexivity, however, cannot afford to be suspended between a homophobic past and a homonormative future, between a politics of rejection and a politics of incorporation. It should be able to envision a space outside these dichotomies to articulate queerness as a "site of resistance" and a "location of radical openness and possibility" (bell hooks as cited in Doty, 1993, p. 3) and queer characters perennially at odds with forces of normalization and domestication.

\section{Notes}

${ }^{1}$ An anthology film usually consists of several different short-films, tied together by a common theme or a brief overlapping event. Besides Ajeeb Dastan Hai Yeh, Bombay Talkies features three other short-films, Star, Sheila ki Jawani and Murabba, directed by Dibakar Banerjee, Zoya Akhtar and Anurag Kashyap respectively. This paper analyzes in detail two of those shorts dealing with queer themes and issues, Ajeeb Dastan and Sheila ki Jawani.

\section{References}

Akhtar, S. (Producer), \& Gowariker, A. (Director). (1995). Baazi [Motion Picture]. India: 786 Aftab Pictures.

Berlant, L., \& Warner, M. (1998). Sex in public. Critical Enquiry, 24 (2), 547-556. Retrieved from http://sites.middlebury.edu/sexandsociety/files/2015/o1/Berlant-and-Warner-Sex-in-Public.pdf

Bose, B., \& Bhattacharyya, S. (Eds.) (2007). Introduction. In The phobic and the erotic: The politics of sexualities in contemporary India (ix-xxxii). Calcutta: Seagull Books.

Doty, A. (1993). Making things perfectly queer: Interpreting mass culture. Minneapolis: University of Minnesota Press.

Dua, A. (Producer), \& Johar, K. (Director). (2013). Ajeeb dastaan hai yeh [Short-film]. Bombay talkies [Anthology Motion picture]. India: Flying Unicorn Entertainment.

Dua, A. (Producer), \& Akhtar, Z. (Director). (2013). Sheila ki jawani [Short-film]. Bombay talkies [Anthology Motion picture]. India: Flying Unicorn Entertainment.

Edelman, L. (2004). No future: Queer theory and the death drive. Durham: Duke University Press.

Gopinath, G. (2000). Queering Bollywood: Alternative sexualities in popular Hindi cinema. In A. Grossman (Ed.), Queer Asian cinema: Shadows in the shade (283-97). New York: New York University Press.

Hansen, E. (Ed.) (1999). Out takes: Essays on queer theory and film. Durham: Duke University Press. 
Joshi, N. (2005, April 5). My brother ... Nikhil. Outlook. Retrieved from http://www.outlookindia.com/magazine/story/my-brother-nikhil/227046

Keats, J. (1818). Letter to George and Thomas Keats. In K. Gupta (Ed.), Romantic Poets (497-498). New Delhi: Worldview.

Kiran, S. (Director). In conversation with Karan Johar, Randeep Hooda, Saqib Saleem, Onir and Sridhar Rangayan. (2014). In A. Davda (Producer), The front row with Anupama Chopra. Mumbai: Star World. Retrieved from http://www.youtube.com/watch?v=BnhpNc_cjkg

Menon, N. (Ed.) (2007). Outing heteronormativity: Nation, citizen, feminist disruptions. In Sexualities (351). New Delhi: Women Unlimited.

Menon, N. (2012). Seeing like a feminist. New Delhi: Penguin.

Prasad, M. (1998). Ideology of the Hindi film. New Delhi: Oxford University Press.

Roy, S. (2013, May 8). Dear Karan Johar, do you really think gay men are like this? First Post. Retrieved from http://www.firstpost.com/bollywood/dear-karan-johar-do-you-really-think-gay-men-are-like-this$758285 \cdot \mathrm{html}$

Sharma, P., \& Sundar, V. (2016, June 27). Indian cinema and its misguided portrayal of the LGBT community. The News Minute. Retrieved from http://www.thenewsminute.com/article/indian-cinemaand-its-misguided-portrayal-lgbt-community-45508

Stryker, S. (1998). The transgender issue: An introduction. GLQ: A journal of lesbian and gay studies. 4 (2), 145-158.

Sullivan, N. (2003). A critical introduction to queer theory. New York: New York University Press.

Suri, S. (Producer), \& Onir (Director). (2005). My brother . . . Nikhil [Motion picture]. India: Four Front Films.

Virdi, J. (2003). The cinematic imagination: Indian popular films as social history. Ranikhet: Permanent Black.

Warner, M. (Ed.). (1993). Fear of a queer planet: Queer politics and social theory. Minneapolis: University of Minnesota Press.

Sameer Chopra teaches English as Assistant Professor at Gargi College, University of Delhi. He holds an MPhil from the Department of English, University of Delhi, and takes special interest in teaching and researching on postcolonial queer culture (texts as well as contexts), post-nineties' popular Hindi cinema and the literary and visual traditions of European Modernism in the early twentieth century. 